\title{
実世界俯瞰画面へのスケッチ動作による 家庭用ロボットの動作指示インタフェース
}

\author{
An Interface for Home Robots by Sketching Behaviors \\ on a Top-down View of a Real World
}

O本田 浩一郎 (東大, JST ERATO 五十嵐デザインインタフェースプロジェクト)
坂本 大介 (東大, JST ERATO 五十嵐デザインインタフェースプロジェクト)
稲見 昌彦 (慶応大, JST ERAT0 五十嵐デザインインタフェースプロジェクト)
五十嵐 健夫 (東大, JST ERAT0 五十嵐デザインインタフェースプロジェクト)

Koichiro HONDA, The University of Tokyo, JST, honda@designinterface.jp, Daisuke SAKAMOTO, The University of Tokyo, JST, Masahiko INAMI, Keio University, JST,

Takeo IGARASHI, The University of Tokyo, JST

\begin{abstract}
Recently, various kinds of home robots have been developed and are getting common in our lives. However, most of the users of home robots do not have the knowledge of hardware and robotics, so they should not be compelled to do any troublesome procedures and manipulation. In this paper, we introduce an intuitive interface for simple and direct manipulation of home robots, focusing on how to interact with robots when we use them. In particular, our system adopts pen-stroke gesture as an input command on computer screen. We designed and implemented several types of gestural commands representing corresponding tasks, and then conducted some usability experiments.
\end{abstract}

Key Words: Home Robots, Human Robot Interaction, Sketch-based Interface, Pen Gesture, GUI

\section{1. 緒言}

一般家庭において，ペットロボットのみならず，実際の仕 事を行うロボットの普及が始まりつつある．家庭用ロボット を含むサービスロボットについての研究はその性能をあげる ことに主眼をおいているが，残念ながら現在のこれらのロボ ットの多くは，まだ実際の日常生活で役に立つものではない. 我々は，家庭用ロボットが現在家庭において普及している電 化製品のように，日常生活に有用で，誰もが簡単に扱うこと のできるものとして普及するためには，その操作インタフェ 一スが重要であると考えている.

電化製品が普及した理由を考えてみたときに，それは家庭 内での家事の時間を短縮することができることが大きな理由 であると考えられる．統計によれば，一般の既婚女性の場合 においては週 29.8 時間を掃除, 洗濯などにかけているが [16], これらの仕事をロボットに任せることができれば，負担をよ り軽減できるだろう。

一方，これまでロボットと呼ばれるものに期待されること は自律的に仕事を実行することであった。しかし，現在の口 ボットにそれを実行させることは難しい，但し，この難しさ は「完全に自律的」に動作寸ることであって, タスクを遂行 寸ること自体ではない. 即ち，完全に自立的に動作できなく とも，ある程度の人の介入を許容してタスクを遂行すること は難しいとは限らない。例えば, 電子レンジや洗濯機は自動 機械ではあるが，我々の指示なしには，我々の意図に即した 結果を出力できない。この点において，家電もロボットでは あるが，良く考えられたインタフェースによってその賢さを 保証されていると考えられる。簡単なインタラクションによ って，ユーザにとって有益な結果が得られるのならば，積極 的にこの相互補完的なアプローチを採用するべきであろうと 考えている.

Human Robot Interaction（以下 HRI）の研究の大きな目的 に人とロボットの共生があるが，本主張はこれを現実的なか

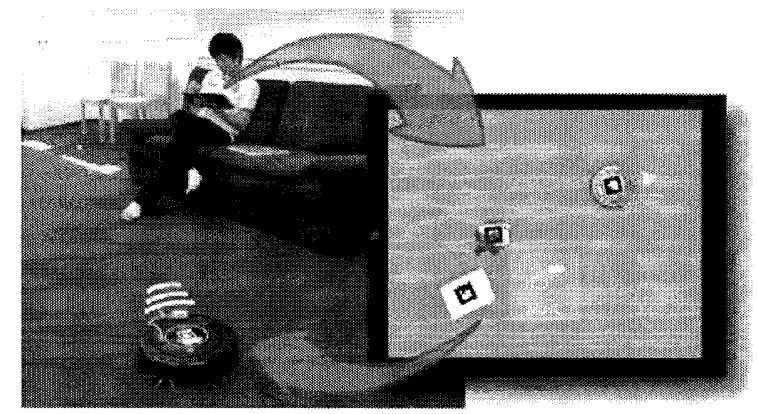

Fig. 1 System concept. In our system, users directly draw gesture commands onto top-down view of a room

たちで実現するものであり，非常に重要な点であると考えて いる。この点において我々は，これまでのロボット開発にお いて，人からロボットに対して指示を与えるためのインタフ エースに注目されることは少なかったと考えている．インタ フェースが人とロボットとのインタラクションを円滑にし， ロボットへの動作指示を簡単かつ，直感的にすることができ れば，ロボットはその活用できる範囲を飛躍的に広め，便利 なものとなる可能性がある，我々はこれに注目する.

本稿では，人とロボットとの相互補完的なアプローチのた めの研究として, 家庭用ロボットのための行動指示インタフ エースを提案する。具体的には，ユーザに提示された実際に 存在する空間の俯瞰画面上においてペンジェスチャにより口 ボットへの動作指示を行うことができるインタフェースを開 発する。本稿では開発システムについても述べたあと，今後 の家庭用ロボットのインタフェースについて議論を行う。

\section{2. 実世界俯瞰画面上への動作指示書き込み インタフェース}

本稿では，家庭用ロボットの例として掃除ロボットを取り 上げ，そのための動作指示インタフェースを提案する。掃除 
は家庭内での仕事の重要な位置を占めているが，未だ自動化 することができていないものであり，ロボットがその役割を 担うことができる可能性があるためである.

本システムにおいては, 部屋の天井に設置したカメラから のリアルタイム映像を利用した俯瞰画面（Top-down View）を 用いて，ペンストロークによってロボットに行動の指示を与 えることが出来る (図 1)。ロボットを操作するためのビュー として, 実際の部屋の様子を提示されていることは重要であ る．家庭用ロボットの操作にはユーザが指示を与えたい場所 と, ロボットの状態を同時に知ることができる必要があるで あろうが，これには，天井からの俯瞰視点が最も操作が容易 であると考えられる。この俯瞰視点を利用寸ることによって， 画面上に実際にスケッチをしているような感覚を提示するこ とが出来ると考えられる，このため，ユーザはより直感的に ロボットへ指示を送ることができると考えられる，ロボット 操作については, 命令の指示設計や, 行動計画が煩雑になり がちであるため, 直感的な操作は重要であろう。

一方で，ロボットの制御を行う上で必要なロボットの位置 と物体の位置の認識についても俯瞰視点は有効である。ロボ ットの動作する平面に垂直に映像を取得することで座標変換 等の処理が不要になり, より誤差を小さくすることが出来る. さらに, キャリブレーションも不要となるため, 設置後ただ ちに使用寸ることもできる。

また，我々はユーザからの指示の入力として，ペンストロ 一クを採用寸る、ペンストロークによる入力は家庭用ロボッ 卜操作に応用しうる有用な点が多くある。例えば，ユーザの 学習が不要であり，一般ユーザにも困難無く扱うことが出来 るほか, 俯瞰画面においては PC 上でのオブジェクト操作のよ うにロボットを操作できる。これまでにも Human Computer Interaction（以下 HCI）の分野において，様々なペンストロ 一クに関する研究が行われてきているが，これは実世界で実 際に動作するロボットにおいても同様に有用であるう。ロボ ットへのインタフェースだけではなく, HRI における研究とし ても，これらの研究は多いに参考になる。また，インタフェ 一スへの入力が点ではなく線であるため, そのまま経路選択 や範囲指定などに使用することができることも重要である.

\section{1 関連研究}

これまでにも俯瞰画面を用いたロボット動作指示手法はい くつか提案されてきている.Skubicらは俯瞰画面上でロボッ 卜の移動軌跡を書くことで，ロボットの操作を実現した [11]. 俯瞰画面上にユーザの書き込み動作によりロボットの動作指 示を実現した研究もある [15] [12][14]。これらの研究では俯 瞰画面を利用し，かつ画面への書き込み動作を利用してロボ ットの動作指示を実現していたが，実世界の画像を使ってい なかった。このため, ロボットが実際に動いているのかどう か，その臨場感を得ることは難しかったと考えられる.

ロボットの直接動作指示手法についても多くの研究が行わ れてきている. Freiらはロボットを直接手で動かし，それを 再生することができるロボットを開発した[13]。細井らは手 持ち型プロジェクターからの映像を利用してロボットの直接 操作を実現した $[9]$.これらの手法は非常に直感的にロボット を操作することが可能な一方で, 長時閒にわたる仕事の指示 や，大きなロボットの指示に怡かないと考えられる.

コンピュータ上での一般的な操作手法（選択，ドラッグア ンドドロップなど）のロボットインタフェース上での実装を 試みた研究についてもすでに存在する。中西らはロボットの 遠隔操作のインタフェースとして, コンピュータのGUI操作を 模したユーザフレンドリな操作システムを提案している [6].

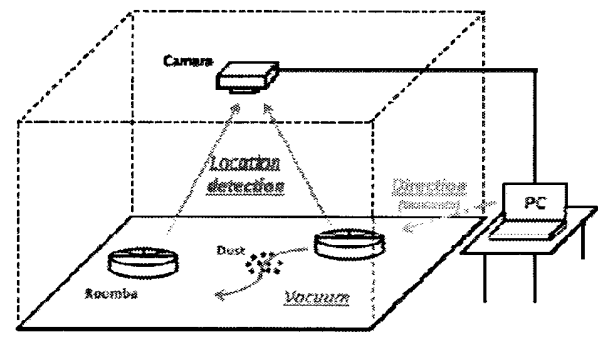

Fig. 2 System Overview

また，Kempらはロボットに対する指示にレーザポインタを使 用することで，クリックして選択するというコンピュータに おけるマウスの操作を模したインタラクションを実世界にお ける物体の選択として実現している $[5]$.

HCIの分野では本稿の提案手法でも採用するペンストロー クに関する研究が数多く行われてきており，その応用事例も 数多く提案されてきている [4][12][7][1]. 我々はこのペンス トロークに関する研究はHRIの分野においても，ロボットの遠 隔操作手法の一つとして非常に有効であると考える.

我々は実世界の俯瞰画面のように高い臨場感を有し，かつ 直感的な操作が可能であるペンストロークを採用寸ることで, ロボットに詳しくないユーザであっても簡単に操作すること ができるインタフェースの開発を目指す。

\section{3. 実装するシステム}

提案する実世界俯瞰画面上でのロボット行動指示インタフ エースの設計と実装について詳述する。また，本稿で開発す るシステムの構成を図 2 に示す.

\section{1 家庭用ロボット}

本稿で開発するシステムでは，家庭用ロボットとして， iRobot 社製の Roomba 570 を使用する. 本ロボットは市販さ れている自走式のロボット掃除機であり，通常の製品として はアルゴリズムに従って部屋の中を自動的に走りながら掃除 させることができるほか，リモコンを利用してユーザが操縦 することも出来る．本ロボットの寸法は直径 $340 \mathrm{~mm} \times$ 高さ $92 \mathrm{~mm}$ であり, 速度は最大で毎秒 $500 \mathrm{~mm}$ 移動である (図 3).

本ロボットには, 開発者向けに API が公開されており, プ ログラムの記述によって，様々な指示が可能である．本シス テムではロボットに Bluetooth-シリアル変換アダプタを接続 し, Bluetooth 通信による遠隔操作を可能とした.

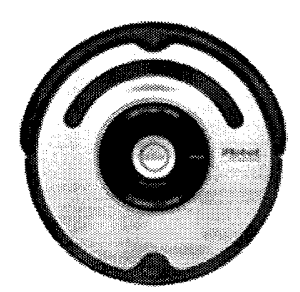

Fig. 3 iRobot Roomba 570

\section{2 俯㒈画面 (Top-down View) の構築}

本システムでは，カメラは市販されている標準的な Web 力 メラを並べたものを用いる。これを天井に設置し，インタフ ェ一スに使用する. 本稿では Logicool 社製の Qcam Pro for Notebooks を使用する. カメラの解像度は $1280 \mathrm{px} \times 960 \mathrm{px}$ に 固定されており，使用する画像では約 $3 \mathrm{~m} \times 2 \mathrm{~m}$ の範囲を取得 することが出来る．また，本システムでのロボットや物体の 位置認識については，ARToolkit を使用している。これにつ 
いては，今後モーションキャプチャシステムなどを使用し， さらに精度良くロボットや物体の位置認識を行うシステムと していく予定である.

\section{3 ペンジェスチャを用いた勳作指示}

本システムではロボットへの動作指示の入力としてペンス トロークによるジェスチャを採用する．本稿で提案するシス テムでは，全ての操作をペンジェスチャで行う。

ペンストロークには，ロボット操作を行う上で有用な点が 数多く存在する．例えば，ペンを使うことによってユーザに 強いる学習が不要であり, 従来の GUI の様にボックスやリス トをクリックするような細かい作業をせずに済むため，ス卜 レスを感じずに指示が行えることが考えられる。

本システムではプロトタイプとして，

- ロボットの移動の指示 (MOVE)

- 掃き掃除の指示 (SPOT)

- 中断 (PAUSE), 再開 (RESUME), 停止動作 (STOP) の指示

- ロボットの充電ステーションに帰る指示 (DOCK)

の 6 種類の動作を, ペンストロークを用いて実装する．実装 するジェスチャを図 4 に示す，以下，各動作の実装について 述べる。

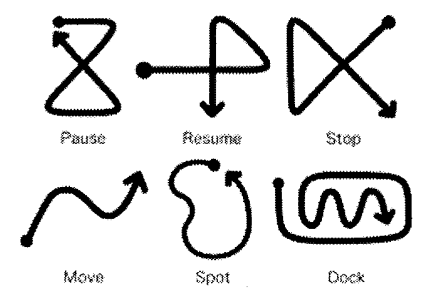

Fig. 4 Gestures for robot direction.

\section{3.1 口ボット自身の移動の指示}

ロボット自身を移動させたい場合，どちらもペンストロー クによって，軌跡を描くことによって行うことが出来る。こ の場合，軌跡を描く開始地点がロボット上であれば，ロボッ 卜の移動指示となる (図 5 左).

ユーザが軌跡を描き終えると, 開始地点から終了地点まで 軌跡が表示される.この軌跡は動作の終了まで表示されるが， これは，指示自体が送信されても実際に移動が完了するまで には時間がかかるため，実際の進行状況が視覚的に確認でき るようにするためである。

中西らの手法[6]では，開始地点と終了地点を指定すること は出来るが，途中経過については指定していない．だが，一 般的に, 経路選択をアルゴリズムによって解決しようとする と, 家具の配置や, 床に落ちている物体を認識しなければな らなくなるため, 非常に問題は難しくなる，その上，ユーザ の意図しない経路, 例えば入ってほしくない場所においては, 結局はユーザの意図を何らかの手段で入力しなければならな い. 本システムにおいては，ユーザは無意識的に障害物をさ けて動作経路を指示すると考えられるため，一般物体認識の 問題を暗黙的に避けることができる.

\subsection{2 揥き揘除の指示}

掃き掃除の指示には，掃き掃除をしたい場所に対して，図 5 右のようにストロークで範囲を指定するジェスチャをする. これによりロボットは指示された領域の中心へ移動し，掃除 を開始する. 自動的に掃除範囲が決められ，ロボットに対し て動くべき軌跡が送信される.
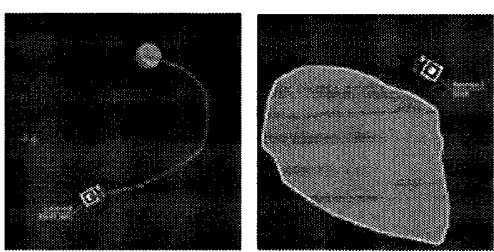

Fig. 5 Task direction. Left: MOVE, Right: SPOT
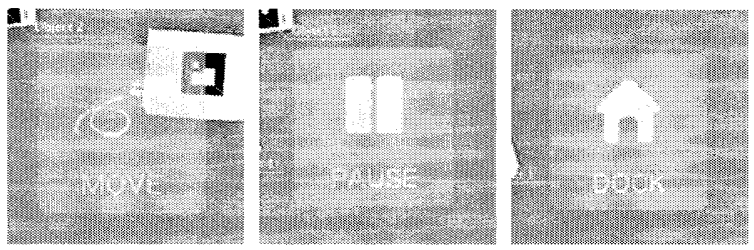

Fig. 6 Visualization of direction result
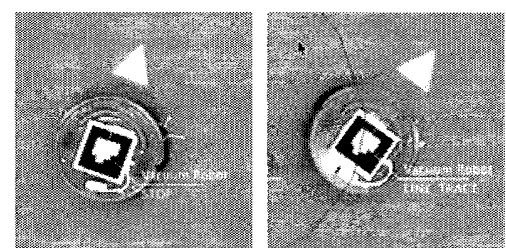

Fig. 7 Visualization of robot status.

\subsection{3 中断, 再開, 停止動作の指示}

ロボットの操作では物理的な移動や動作が伴うため，指示 してから動作が完了するまでに時間がかかることが多い。そ のため，作業を実行中に作業場所近辺の状況が変わったり， 違う指示を与えたりする必要が出てくる可能性もある。 そこ で, 行っている作業を途中で中断させたり, 再開させたりで きることも必要である.

本システムでは動作の中断, 動作の再開を, 簡単な記号認 識によって実装を行った。ジェスチャ認識のアルゴリズムは, Wobbrockらの手法[8]を参考にしており，画面の任意の場所に， 決められた記号（中断は砂時計マーク，再開は再生ボタンマ 一ク）が描かれると，実際にその動作を行う。また，動作お よび作業の停止や，ロボットの定位置（充電ステーション） に戻るといった指示についても実装を行った.

\section{4 ユーザに提示される情報}

ペンジェスチャによる動作指示においては，ジェスチャの 入力が成功したか否かを判断するための情報提示が必要であ る。また，ユーザはロボットが現在どのような状態なのかを 知りたい欲求もあるだろう。このため，本システムではジェ スチャの入力が成功した場合に，ただちにその結果を知らせ るための情報を出力することとした（図 6 )。 ままた，ロボット の状態を示すため, ロボットの名前および状態を俯瞰画像に オーバーレイ表示させている(図 7).

\section{4. 議論}

本稿ではペンジェスチャによるロボットへの行動指示イン タフェースを提案し，プロトタイプを開発した。

\section{1 実世界俯瞰画面を用いたロボット操作}

本システムではロボット操作インタフェースとして実世界 での実世界俯瞰画面映像を利用した。これまでの俯瞰画面を 用いた研究では実世界の画像を用いておらず, このため, 実 際にロボットを操作している感覚を提示することは難しかっ た，本システムでは実世界の画面を利用することで，実際に ロボットが動いている樣子をリアルタイムで確認しながら口 ボットの操作を行うことができるインタフェースを構築する ことが可能となった．さらに，俯瞰画面を提示し，その上で 
ロボットの行動を指示することが可能となったため，ユーザ はロボットの向きの誤認識をすることなく，自然な動作指示 が可能となった.

これまでにも俯瞰画面以外にロボット視点で操作を行うイ ンタフェースについても様々に提案されてきているが，本シ ステムではロボットだけではなくソフトウェアの知識もない ユーザと主な対象としていた．この点においても俯瞰画面は, ロボットの行動する範囲を把握し, 適切にロボットを移動さ せることを想像することが可能な環境として適切であると考 えている。

\section{2 ロボット動作の非同期性}

家庭用ロボットに求められる機能の中でも重要なものの一 つに動作の非同期性がある。電化製品は家事に関する指示を, それを行う機器に対して指示を行うことができ，かつ，それ を非同期化させることが可能であったため，広く普及したと 考えられる. 本システムはロボットに対する指示を非同期化 することができるという点で，重要であろう。ただし，現在 はロボットへの動作指示がただちに実行されてしまうように なっているため, 完全に非同期化された訳ではない.しかし， 動作の実行についてディレイを設けることや，指定時刻に実 行するようなシステムを実装することは難しくないため，今 後実装する予定である。

\section{3 他のロボットシステムへの応用可能性}

本システムは家庭用ロボット，特に掃除ロボットに注目し たものであった．我々は，もちろん掃除ロボットのみに注目 している訳ではなく，このため，他のロボットへ本稿の知見 を応用する必要がある。例えば，ものを運ぶことができるロ ボットに対して，ものを取ってくる指令を出す際には本稿の インタフェースは有効であろう。しかし，また，他のサービ スロボット，特に人型ロボットへの応用可能性について考え てみたときに，ストロークジェスチャのみでは難しいことが 考えられる. Glasらは人に対して対話を通してサービスを提 供するロボットの遠隔操作インタフェースを提案した[10].こ のインタフェースではロボットからの情報をビジュアルにユ ーザ（オペレータ）に提示し，またロボットが可能な行動を 併せて提示することで, 複数台の人型ロボットの操作を可能 にした。しかし，ナビゲーション動作については扱っておら ず，このため，移動をすることはできなかった。本システム を用いることで，人型ロボットのナビゲーションについては ユーザが自由に行うことができるようになるであるう。

本システムではロボットを 1 台のみ扱っていたが，ロボッ トが現在よりもさらに普及し，複数台のロボットが同時に存 在すると想定される未来においては，インタフェース，およ びロボットの自律性がさらに求められる，例えば，掃除して 欲しい範囲を指定するだけで，適切なロボットが選択され， 実行されることが求められるようになるであろう。今後はこ のようなシステムについても設計, 開発を行っていく予定で ある。

\section{5. 結言}

本稿では実世界の俯瞰画面を用いたロボットへの動作指示 インタフェースのプロトタイプを開発した．本システムでは ペンストロークを用いたロボットへの直感的な指示が可能で あった，提案した手法は家電としての家庭用ロボットにとっ て重要な, 非同期的な操作手法として有効であることがわか った.

本稿で提案した俯瞰画面を用いた動作指示システムは天井 にカメラを設置することで，1. キャリブレーションが不要で あり，2，座標変換も不要であることから，システムの設置か
ら開始までに手間がかからない。このため，多くの家庭で簡 単に使用することができるシステムとして実装されたと考え ている.

本稿ではコンピュータ画面上でのペンストロークを入力と して与えていたが，本質的にはストロークによる入力であれ ば同等の処理が行える。例えばレーザポインタ等であっても 操作を行うことが出来る。これはつまり，実世界でのポイン ティングジェスチャをレーザによって行うことができ，より ユーザにとって自然なロボットへの実世界指向インタフェー スとなりえる可能性があるということである.

ストロークジェスチャによるインタフェースはコンピュー 夕画面上だけではなく，実世界により親和性のあるインタラ クション手法であると考えられる。今後はさらにこれらの研 究を進めていく予定である。

\section{文 献}

[1] C. Alvarado and R. Davis. Preserving the Free-dom of Paper in a Computer-based Sketch Tool.Proceedings of $\mathrm{HCI}$ International, 2001.

[2] A. Forsberg, M. Dieterich, and R. Zeleznik. The Music Notepad. Proceedings of the 11th Annual ACM Symposium on User Interface Software and Technology, pp. 203-210, 1998.

[3] J. Hersch and L. S. Stratton. Housework and Wages. The Journal of Human Resources, 37(1):217-229, 2002.

[4] T. Igarashi, S. Matsuoka, and H. Tanaka. Teddy: A Sketching Interface for 3D Freeform Design. Proceedings of the 26th Annual Conference on Computer Graphics and Interactive Techniques, pp. 409-416, 1999.

[5] C. Kemp, C. Anderson, H. Nguyen, A. Trevor, and Z. Xu. A Point-and-Click Interface for the Real World: Laser Designation of Objects for Mobile Manipulation. Proceedings of the 3rd International Conference on Human Robot Interaction, pp. 241-248, 2008.

[6] 中西英之，村上友樹：案内ロボットの遠隔操作のための GUI の 提案，情報処理学会研究報告ヒューマンコンピュータインタラ クション, pp. 79-86(2008).

[7] K. Perlin. Quikwriting: Continuous Stylus-based Text Entry. Proceedings of the 11th Annual ACM Symposium on User Interface Software and Technology, pp. 215-216, 1998.

[8] J. Wobbrock, A. Wilson, and Y. Li. Gestures without Libraries, Toolkits or Training: A \$1 Recognizer for User Interface Prototypes. Proceedings of the 20th Annual ACM Symposium on User Interface Software and Technology, pp. 159-168, 2007.

[9] 細井一弘, ダオヴィンニン, 森 晶洋, 杉本雅則：モバイルデ イスプレイを用いた直感的なヒューマンロボットインタラクシ ヨンの提案, インタラクション 2008 論文集, pp. 17-24 (2008).

[10] Glas, D. F., Kanda, T., Ishiguro, H., and Hagita, N. Simultaneous teleoperation of multiple social robots. In Proceedings of HRI '08, 311-318, 2008.

[11] Skubic, M., Anderson, D., Blisard, S., Perzanowski, D. and Schultz, A., Using a hand-drawn sketch to control a team of robots, In Auton. Robots, 22 (4), 399-410, 2007.

[12] Setalaphruk, V., Ueno, A, Kume, I., Kono, Y. and Kidode, M. Robot Navigation in Corridor Environ-ments using a Sketch Floor Map. Proceedings of the 5th IEEE International Symposium on Computational Intelligence in Robotics and Automation, pp.544-551, 2003.

[13] Frei, P., Su, V., Mikhak, B., and Ishii, H. curlybot: designing a new class of computational toys. In Proc. of the SIGCHI Conference on Human Factors in Computing Systems, pp. 129-136, 2000.

[14] Lapides, P., Sharlin, E., and Costa Sousa, M. Three dimensional tangible user interface for controlling a robotic team. In Proc. of the 3rd ACM/IEEE international Conference on Human Robot interaction, pp. 343-350, 2008

[15] Lundberg, C., Barck-Holst, C., Folkeson, J. and Christensen H.I. PDA interface for a field robot. In Proc. 2003 IEEE/RSJ Intl. Conf. Intelligent Robots and Systems, pp. 2882-2887, 2003.

[16] J. Hersch and L. S. Stratton. Housework and Wages. The Journal of Human Resources, 37(1):217?229, 2002. 